http://doi.org/10.15359/ree.12-1.11

\title{
LOS COMIENZOS DEL CIDE
}

\author{
Oscar Benavides ${ }^{l}$ \\ Jubilado de la Universidd Nacional \\ Heredia, Costa Rica
}

Recibido el 1 de noviembre 2007• Aprobado el 5 de diciembre 2007

El tema de la educación ocupa siempre un lugar en nuestras reflexiones. Tanto cuando pensamos en la formación de las personas como cuando pretendemos mejores formas de vida para una determinada población.

Los países desarrollados, cuentan con facilidades materiales que proporcionan altos niveles de desarrollo socioeconómico y muy calificados estándares en la calidad de vida para sus habitantes. Cuando buscamos las causas de esa condición, hallamos que los soportes principales están enraizados en una excelente educación, creada por las decisiones sociopolíticas de los países. El fenómeno se da por la prioridad económica conferida a la educación. Sabemos que esa realidad no es una característica común en la mayoría de nuestros países. No es arriesgado decir que en la realidad latinoamericana, la atención que se le brinda a los procesos educativos formales no gozan, ni por asomo, de una prioridad importante en la gestión de los gobiernos.

Sabiamente, don Omar Dengo dijo “... gastar pródigamente en educación no es una cuestión de finanzas, sino una cuestión de honor, de decoro nacional”. En una forma más utilitaria, quizá, la UNESCO ha declarado que "Ningún país podrá avanzar en su desarrollo más allá de donde llegue su nivel educativo ... la educación es un instrumento fundamental en la liberación de las mejores potencialidades del ser humano para alcanzar una sociedad más justa y equilibrada..." (UNESCO, CEPAL, OEA, 1979, p. 2).

Ambos pensamientos: uno personal y otro institucional, llaman la atención sobre la importancia de invertir convenientemente en educación. Las comparaciones entre países que han puesto a la educación como una estrategia esencial para el desarrollo, como política de estado, con otros que no lo han hecho, indican diferencias impresionantes. Los que han puesto el dinero para educar con excelencia, logran, además del desarrollo personal y calidad de vida de sus habitantes, altos índices de conocimiento para su desarrollo científico y tecnológico. Mientras que en los otros, su desarrollo se estanca o decae. Las personas con una educación que estimule su desarrollo son quienes producen riqueza, en el mejor sentido de la palabra.

Los antecedentes y los primeros años del CIDE estuvieron matizados, en buena medida, por ideas y acciones desde dicha perspectiva. Entonces, trabajamos con ahínco para producir aportes

Actualmente es profesor jubilado de la Universidad Nacional [UNA] (1983-1990). Fue el último decano de la Escuela de Educación y el primer decano del Centro de Investigación y Docencia en Educación (CIDE). 
educativos de calidad, con la idea de crear condiciones para que el desarrollo educativo tomara una prioridad tangible en la gestión universitaria y nacional.

Expresé algunas ideas que posteriormente inspiraron ese proceso, con motivo de la elección del Sub-Director de la Escuela de Educación (1976). Ello a raíz de la necesidad de potenciar la labor de esa Escuela y la herencia de las instituciones educativas precedentes:

...pienso que la Escuela de Educación de la Universidad Nacional debe intensificar más la investigación de los problemas y necesidades de la sociedad costarricense para formar educadores que se conviertan en positivos agentes de cambio.

Ese impulso ocurrió en un ambiente de fervor por la reciente creación de esta Universidad. Por ello, esta fue, tal vez, una tímida declaración de un camino que a la postre se dibujaría mejor.

Más adelante, con motivo de la elección del Director de la Escuela de Educación (1981), aludimos al legado de la antigua Escuela Normal y la herencia de sus mentores, como fuerza impulsora de los primeros pasos para la creación - de hecho- del que sería el Centro de Investigación y Docencia en Educación, tal como se consignaba en el Estatuto Orgánico. Estimo que los impulsos renovadores que en su momento formaron parte de la vida del CIDE tenían como savia nutriente la mística heredada de la Normal. La UNA fue la heredera directa de la principal tradición pedagógica de Costa Rica. Heredia, como ciudad universitaria naciente, no contaba con tradición en otras disciplinas; en educación, en cambio, era el referente al que miraban espontáneamente los educadores nacionales como la fuente de formación y renovación.

En las propuestas para la gestión como Director de la Escuela de Educación, estuve convencido de la necesidad de un cambio que permitiera impulsar las ideas y realizaciones que ya estaban dando frutos en esta Escuela, por ello manifesté:

Pienso que nuestra institución, a corto plazo, debe convertirse en el CIDE, de acuerdo como lo establece el Estatuto Orgánico... en la transformación estructural que propongo destaco el siguiente objetivo fundamental: Creación de un modelo organizativo con más potencial para el desarrollo y desarrollo de un modelo académico con más capacidad para el crecimiento cualitativo.

Hoy creo, que, sin romper la continuidad de las instituciones precedentes, la concreción de este propósito significó un punto de inflexión en el proceso de desarrollo educativo que ofrecía la Universidad Nacional. En esta misma propuesta consideramos lo que poco tiempo después construirían los retos principales del CIDE, a saber: transformación administrativa, establecimiento de un modelo para el desarrollo académico e impulso al mejoramiento profesional del personal académico y administrativo.

Como resultado de un trabajo tesonero de todo el personal de la Escuela de Educación, su Asamblea conoció y aprobó, en agosto de 1982, el proyecto que entregamos al Consejo Universitario. Este fue el antecedente inmediato para el acuerdo de ese Consejo, decretado en la sesión $\mathrm{N}^{\circ} 653$ del 23 de diciembre de ese mismo año, el cual dice, en el punto primero, lo siguiente:

Autorizar el funcionamiento del Centro de Investigación y Docencia en Educación, CIDE, de acuerdo con lo establecido en los artículos 60 y 61 del Estatuto Orgánico y el transitorio al artículo 60 del mismo Estatuto. 
Con esta disposición, concluyó la formalidad reglamentaria para iniciar la parte sustantiva de un órgano universitario en Ciencias de la Educación.

Las potestades dadas por el Consejo Universitario colocaron a la nueva institución (CIDE) en una ventajosa posición para el cambio esperado. Paradójicamente, nos ponía en una difícil coyuntura histórica, que ponía a prueba la capacidad institucional para concretar el desarrollo previsto. En esas condiciones, teníamos abiertas las posibilidades para responder a las expectativas que el conjunto de la Universidad había puesto en el nuevo Centro.

Los principales retos de la etapa inicial del CIDE, fueron:

- Desarrollar un programa de formación con estudios de posgrado para el personal académico.

- Integrar un equipo de profesionales en educación, sólidamente formado y con reconocidas capacidades para trabajar en equipo, a efecto de llevar a cabo la gestión administrativa y académica del Centro.

- Incorporar al personal administrativo en tareas y funciones protagónicas en los procesos de cambio.

- $\quad$ Estructurar un modelo de desarrollo académico con características integradoras de las funciones básicas de la Universidad, a saber: investigación, docencia y extensión. Además, mostrar la capacidad para lograr una participación intrauniversitaria de vanguardia en materia educativa como disciplina.

- $\quad$ Presentar aportes innovadores respecto del enfoque hacia la educación para la población de 0 a 12 años de edad.

- Dotar a la institución de la infraestructura apropiada para las nuevas necesidades.

- Cultivar una cultura de calidad, enfocada a la excelencia académica, como estrategia para conquistar un posicionamiento positivo en el ámbito interno, en las relaciones académicas inter-universitarias y en la comunidad nacional.

- Contribuir eficazmente en la solución de problemas de la educación costarricense, en calidad, diversidad y cobertura.

- $\quad$ Proyectar al CIDE fuera de Costa Rica.

Esos desafíos, a modo de retos apremiantes, surgen, a mi juicio, de dos fuentes: una nueva condición orgánica y el resultado de un ideario que compartíamos los participantes de las propuestas de diseño conceptual y operativo de esta Institución. A la postre, la experiencia demostró el acierto de nuestras aspiraciones. Sin duda, el éxito fue notorio en la consecución de resultados concretos en cada una de las áreas que los retos iniciales demandaban.

El CIDE se fortaleció con profesionales altamente calificados, con estudios en el nivel de posgrado, en nuestros centros de educación superior y en otros países.

Progresivamente, las relaciones con instituciones de tradición en el campo académico y organismos oficiales en la gestión del sistema educativo nacional, se constituyeron en hábito y práctica de cooperación en los asuntos educativos. Es justo decir que el CIDE mostró su fisonomía. Con pocos años de su fundación, su presencia adquirió relevancia por la honestidad académica y la calidad de sus aportes. A la postre, nuestra participación en el campo educativo tuvo un considerable peso específico, que le valió de sustento para continuar en su proceso de fortalecimiento.

Gracias a la participación de excelentes profesionales, se constituyó un equipo que impulsó el Modelo Organizativo para el Desarrollo Académico del Centro de Investigación y Docencia 
en Educación (1986). De su contenido -el cual fortaleció y reorientó las acciones del Centrotomo conceptos que marcan el cometido del CIDE. Se enfatiza que el centro gravitacional de la Institución es el desarrollo académico, y se destaca la vocación para formar recursos humanos para los diversos niveles y modalidades de la educación, así como para la producción científica, tecnológica y humanista en educación.

Sin desconocer los altos y bajos normales en los procesos de cambio, gracias a este modelo académico, se acrisolaron muchas conquistas académicas, como: rediseño de carreras, mayor impulso a la investigación, mejores relaciones intrauniversitarias, planes de extensión y una mayor integración orgánica de todas las acciones del CIDE.

El objetivo de procurar el desarrollo cualitativo se manifestó en la vivencia permanente de una cultura de calidad. En el devenir de las tareas universitarias, la presencia del CIDE adquirió paulatinamente, mayor relevancia dentro de la Universidad y en el ámbito nacional.

Entre los aportes renovadores para la educación de la población de 0 a 12 años de edad se destaca la creación del Instituto del Niño (junio de 1988). Este sería un órgano concebido para estudiar la realidad de la niñez costarricense, lo mismo que la creación de propuestas de solución a los principales problemas que impiden el desarrollo de las capacidades para acceder a los procesos educativos y tener éxito en el ambiente escolar y otras áreas de su desarrollo.

Un hecho importante del proceso, fue el mejoramiento de la infraestructura. La planta física nueva contribuyó a revitalizar el impulso de nuestro desarrollo. La comunidad universitaria cuenta con el Auditorio que, para su confirmación como un símbolo del CIDE, lleva el nombre del insigne educador herediano: Marco Tulio Salazar.

Retrospectivamente, sobresalen en el tiempo algunas cumbres de los comienzos del CIDE, en la época que tuve el honor de estar entre quienes le dieron vida. Hoy podemos caracterizar con rasgos propios a una institución que, entre otras cosas, logró:

- $\quad$ Una mística.

- Constituir un equipo con personas de un sólido nivel académico.

- Compartir los procesos de cambio con personal administrativo comprometido con un ideario.

- Un modelo académico que propició el avance en la búsqueda de soluciones para la educación costarricense.

- Los méritos para ocupar un lugar de valor en la comunidad universitaria nacional.

- Crear un órgano para lograr entender y atender la población nacional en los primeros años de su desarrollo personal y educativo: El Instituto del Niño.

- $\quad$ Las cualidades institucionales cuyas visiones y productos trascienden hoy nuestras fronteras.

- $\quad$ Tener como norte el concepto de calidad.

Finalmente, repetiré una idea que alguna vez dije: El CIDE tiene rumbo. Tiene una suerte de fuerza que lo impulsa. Quienes hemos vivido su nacimiento y evolución, de alguna manera hemos impregnado energía vital que lo define como una institución vigorosa, que se renueva en forma permanente. Entre todo, hemos logrado una entidad de vanguardia en el pensamiento y en la acción universitaria. 


\section{REFERENCIAS}

Universidad Nacional [UNA]. Estatuto orgánico de la Universidad Nacional. Heredia, Costa Rica.

Organización de las Naciones Unidad para la Educación, la Ciencia y la Cultura [UNESCO]. (1979). Declaración de México. México. 